\title{
Formação de Grupos Colaborativos em Cursos a Distância via Web utilizando Técnicas de Inteligência Artificial
}

\section{Resumo}

\author{
Sidnei Renato Silveira** \\ Dante Augusto Couto Barone***
}

Este artigo apresenta a tese de doutorado em Ciência da Computação na linha de pesquisa de Inteligência Artificial, dentro da área de IAD - Inteligência Artificial Distribuída (mais especificamente os Sistemas Multiagentes - SMA). O trabalho aborda a formação de grupos colaborativos em um ambiente multiagente interativo de aprendizagem na web, através da utilização de técnicas de Inteligência Artificial, aplicadas na implementação de uma arquitetura de agentes modelados com algoritmos genéticos, integrada a um ambiente colaborativo de aprendizagem, o TelEduc.

Palavras-Chave: grupos colaborativos, inteligência artificial, sistemas multiagentes, algoritmos genéticos

Building Collaborative Groups in Web Distance Courses through Artificial Intelligence Techniques

\begin{abstract}
This text has as objective to present a doctorate thesis in Computer Science in PPGCUFRGS. The subject of the paper is fit in the research of Artificial Intelligence, inside DAI area - Distributed Artificial Intelligence (more specifically the Multi Agent Systems - MAS). The paper considers the use of agents education environments, through modeling of agents using genetic algorithms, to build collaborative groups. The work proposes a multi agent architecture modeling of genetic algorithms, integrated with a collaborative educational environment, the TelEduc.
\end{abstract}

Keywords: collaborative groups, artificial intelligence, multi agent systems, genetic algorithms

\section{INTRODUÇÃO}

Com a revolução tecnológica e científica presente na sociedade atual, a educação passa a delinear novas formas de interação entre professores e alunos. A educação a distância, com certeza, é a modalidade de educação que mais usufrui disto, principalmente através da web, com o apoio de ambientes virtuais, que encorajam a participação dos

\footnotetext{
* Mestre e Doutorando em Ciência da Computação pelo Programa de Pós-Graduação em Computação (PPGCUFRGS). Professor Adjunto da Faculdade de Informática -ULBRA-Canoas, Professor Adjunto do Centro Universitário Ritter dos Reis - UniRitter e Coordenador do Curso de Bacharelado em Sistemas de Informação da FACENSA. sidnei@inf.ufrgs.br

** Professor do Programa de Pós-Graduação em Computação (PPGC-UFRGS) e do Pós-Graduação em Informática na Educação (PGIE/UFRGS). barone@inf.ufrgs.br
} 
envolvidos no processo educacional, independente de tempo e espaço. A colaboração e cooperação entre os envolvidos é de fundamental importância para que ocorra, efetivamente, a interação entre os integrantes de um ambiente virtual de ensino e aprendizagem.

Acreditando que a cooperação é um processo extremamente importante para a Educação a Distância, este artigo apresenta uma proposta para a formação de grupos colaborativos, a partir de critérios que poderão ser estabelecidos (configurados) pelo professor, dentro de um ambiente multiagente interativo de aprendizagem ${ }^{1}$.

\subsection{Educação a Distância e a Formação de Grupos Colaborativos}

A utilização dos computadores e da Internet alavancou a área de EAD (Educação a Distância). A Educação a Distância Mediada por Computadores (EDMC) é uma das áreas de pesquisa mais promissoras da Informática na Educação. As escolas e, principalmente, as universidades estão investindo em novas formas de ensino, através da utilização do computador, da Internet e de cursos a distância. A interatividade necessária para o bom andamento de um curso a distância pode ser estimulada através da criação de grupos colaborativos. Inúmeros pesquisadores da área de Educação afirmam que o trabalho em grupo é de extrema importância para o desenvolvimento da aprendizagem. Segundo Piaget citado por Minicucci (1997), a formação intelectual é privilegiada quando existe a livre cooperação entre os participantes de um grupo. Mediante as experiências de grupo, os participantes aprendem que podem ser adotados diferentes pontos de vista e que, os mesmos estão correlacionados e são complementares. Através da troca de idéias entre os integrantes de um grupo é possível estimular o raciocínio lógico de cada um. Utilizando-se de um ambiente virtual de EAD, os alunos, na maioria das vezes, não se conhecem pessoalmente e/ou não se encontram de forma presencial, mas a cooperação continua sendo importante para $o$ estabelecimento das relações sociais.

A formação de grupos colaborativos em ambientes virtuais de EAD é dificultada, principalmente por dois aspectos: 1) os integrantes do ambiente em questão, na maioria das vezes, não se conhecem pessoalmente e 2) os integrantes encontram-se em locais geograficamente dispersos. Estes aspectos fazem com que a formação dos grupos colaborativos em ambientes de EAD seja realizada, geralmente, de forma aleatória, não sendo considerado nenhum critério específico. Além disso, quando indivíduos reúnem-se em grupos, representam diversos papéis. Segundo Mucchielli citado por Minicucci (1997), os papéis são utilizados para representar atitudes préconcebidas. Este autor coloca que, mesmo em comportamentos espontâneos dentro do grupo, os integrantes nunca escapam a esses papéis. Sendo assim, não é o indivíduo quem decide seu papel. Neste sentido, o presente trabalho propõe, além da formação dos grupos colaborativos, a definição do papel que cada um dos integrantes irá desempenhar no grupo, de acordo com o seu estilo cognitivo.

\section{FORMAÇÃO DOS GRUPOS COLABORATIVOS}

Para realizar a formação dos grupos colaborativos foram utilizadas técnicas de Inteligência Artificial, entre elas os Algoritmos Genéticos e os Sistemas Multiagentes. Os grupos colaborativos são formados a partir de critérios definidos pelo professor e os papéis dos integrantes são baseados no estilo cognitivo, informação oriunda do modelo

\footnotetext{
${ }^{1}$ Projeto AMIA (Ambiente Multiagente Interativo de Aprendizagem), financiado pelo CNPq.

$2 \longrightarrow$ V. 3 N $^{\circ} 2$, Novembro, 2005
} 
de aluno. Criou-se uma arquitetura de agentes integrada ao ambiente de EAD TelEduc (TelEduc, 2005).

\subsection{Modelo de Aluno e Arquitetura de Agentes Proposta}

O modelo de aluno utilizado pelo agente modela aluno baseia-se nos estudos desenvolvidos no Projeto AMIA, tendo sua origem na aplicação do instrumento elaborado e validado por Bariani (1998) e implementado computacionalmente por Geller (2004). Este modelo compreende os alunos em seis estilos cognitivos: 1) Convergente; 2) Divergente; 3) Holista; 4) Serialista; 5) Reflexivo e 6) Impulsivo.

A arquitetura de agentes está integrada ao ambiente TelEduc. Na arquitetura implementada tem-se cinco agentes, cujas funções são:

- agente de comunicação: responsável por receber as requisições dos outros agentes e encaminhá-las ao agente que pode desempenhar a tarefa solicitada, atuando como um facilitador;

- agente modela aluno: responsável por gerenciar as informações que dizem respeito ao modelo de aluno e disponibilizá-las aos demais agentes de forma dinâmica;

- agente forma grupo colaborativo: através das características definidas pelo professor e das informações extraídas do modelo de aluno, forma grupos de estudo colaborativos;

- agente adaptativo de conteúdo: responsável por adaptar o conteúdo de acordo com as informações do modelo do aluno;

- agente adaptativo de avaliação: este agente é encarregado de adaptar o processo de avaliação de acordo com o perfil do aluno, disponibilizando as ferramentas mais adequadas dentro do ambiente. Além disso, de acordo com critérios estabelecidos pelo professor, este agente fornecerá subsídios para o agente modela aluno e para o agente adaptativo de conteúdo, com relação ao acompanhamento do aluno durante a utilização das ferramentas de avaliação.

\subsection{Agente Forma Grupo Colaborativo}

A partir dos estilos cognitivos compreendidos pelo modelo de aluno, o agente forma grupo colaborativo organiza os alunos em grupos, estabelecendo os papéis que os integrantes dos mesmos deverão desempenhar. Os papéis utilizados foram estabelecidos de acordo com a classificação proposta por Belbin (2001) citador por Carneiro (2003), sendo eles: 1) Planejador, 2) Coordenador, 3) Investigador de Recursos, 4) Monitor/Avaliador, 5) Finalizador/Implementador e 6) Especialista.

De acordo com os estilos cognitivos dominantes de cada aluno, o agente designará o papel mais adequado para cada integrante do grupo, seguindo os critérios estabelecidos pelo professor. Os papéis, segundo o estilo cognitivo preferencial, foram estabelecidos como mostra a Tabela 1.

Tabela 1 - Designação de Papéis aos Integrantes do Grupo

\begin{tabular}{|c|c|}
\hline $\begin{array}{c}\text { Estilo Cognitivo Preferencial } \\
\text { (ou Dominante) }\end{array}$ & Papel a ser desempenhado no grupo \\
\hline Impulsivo & Investigador de Recursos \\
\hline Reflexivo & Monitor/Avaliador \\
\hline Holista & Coordenador \\
\hline Serialista & Especialista \\
\hline
\end{tabular}




\begin{tabular}{|c|c|}
\hline Convergente & Finalizador/Implementador \\
\hline Divergente & Planejador \\
\hline
\end{tabular}

A estrutura de dados para armazenar as características dos alunos para a formação dos grupos foi constituída a partir de uma matriz tridimensional. Nesta matriz, cada uma das linhas representa um possível grupo a ser formado. As colunas representam cada um dos alunos do grupo. A terceira dimensão, denominada plano, representa as características individuais de cada aluno (estilos dominantes, sexo, faixa etária e localização geográfica). Esta matriz é demonstrada na Figura 1.

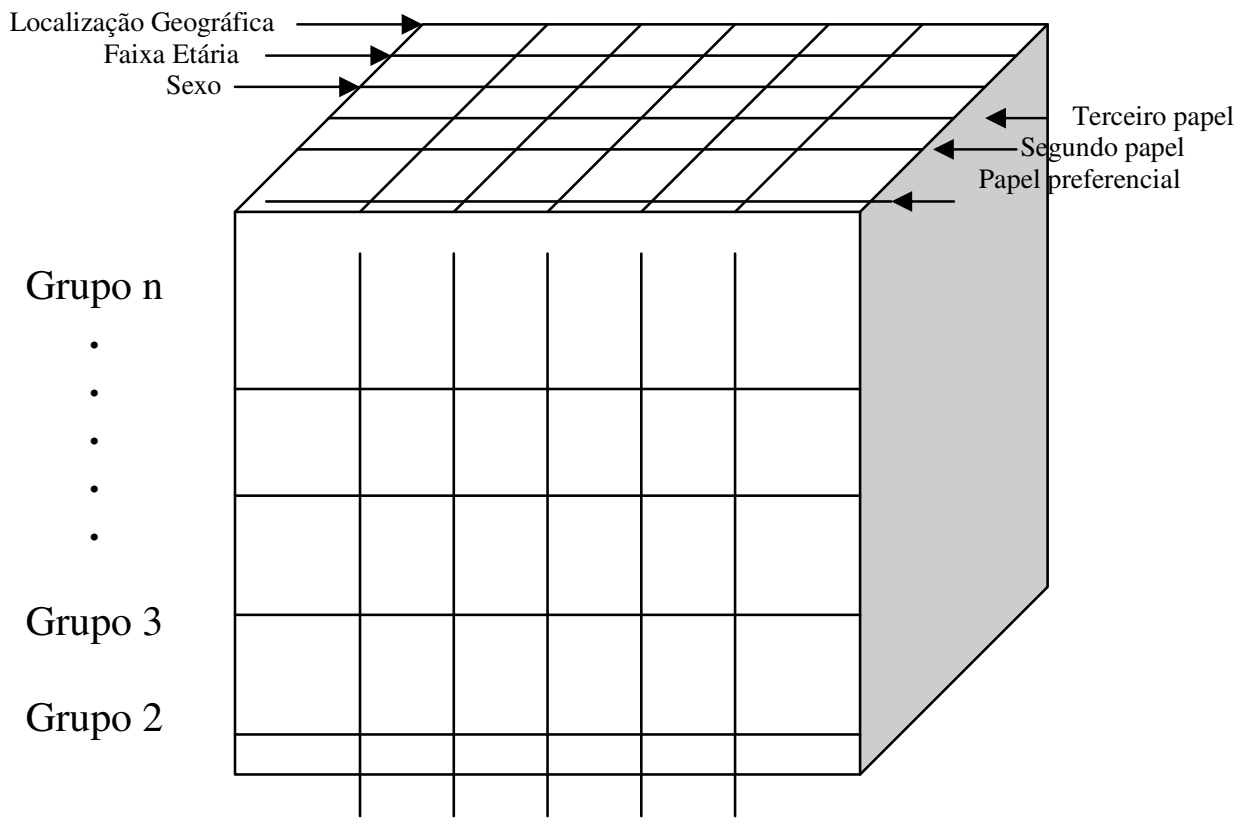

$\begin{array}{llllll}\text { Alunos: } & 1 & 2 & 3 & 4 & 5\end{array}$

Figura 1 - Estrutura de Dados para Formação dos Grupos Colaborativos

Através da utilização de um algoritmo genético (Davis, 1991), o agente implementado define a melhor combinação de alunos para um grupo. Para a formação dos grupos colaborativos utilizaram-se as seguintes definições:

- Inicialmente, são buscados os estilos cognitivos preferenciais armazenados para cada aluno do curso. Estes estilos permitem a classificação dos papéis de cada integrante do grupo. Além do estilo cognitivo, o professor também pode utilizar como critérios o sexo, idade e localização dos integrantes do grupo. Estes critérios são armazenados numa matriz tridimensional onde as linhas representam os grupos, as colunas os alunos e os planos armazenam os critérios selecionados para a formação dos grupos (Figura 1);

- O professor, através de uma interface disponibilizada pelo agente forma grupo colaborativo (conforme Figura 3), pode escolher se o grupo formado deve ser heterogêneo ou homogêneo e definir os critérios desejados (estilo cognitivo - os 
três papéis preferenciais que o aluno pode assumir, sexo, faixa etária e localização geográfica), como mostra o exemplo de cromossomo na Figura 2:

\begin{tabular}{|l|l|l|l|l|l|}
\hline Gene 1 & Gene 2 & Gene 3 & Gene 4 & Gene 5 & Gene 6 \\
\hline $\begin{array}{l}\text { Estilo } \\
\text { cognitivo }\end{array}$ & $\begin{array}{l}\text { Estilo } \\
\text { cognitivo }\end{array}$ & $\begin{array}{l}\text { Estilo } \\
\text { cognitivo }\end{array}$ & $\begin{array}{l}\text { Estilo } \\
\text { cognitivo }\end{array}$ & $\begin{array}{l}\text { Estilo } \\
\text { cognitivo }\end{array}$ & $\begin{array}{l}\text { Estilo } \\
\text { cognitivo }\end{array}$ \\
\hline $\begin{array}{l}\text { Segundo } \\
\text { estilo }\end{array}$ & $\begin{array}{l}\text { Segundo } \\
\text { estilo }\end{array}$ & $\begin{array}{l}\text { Segundo } \\
\text { estilo }\end{array}$ & $\begin{array}{l}\text { Segundo } \\
\text { estilo }\end{array}$ & $\begin{array}{l}\text { Segundo } \\
\text { estilo }\end{array}$ & $\begin{array}{l}\text { Segundo } \\
\text { estilo }\end{array}$ \\
\hline $\begin{array}{l}\text { Terceiro } \\
\text { estilo }\end{array}$ & $\begin{array}{l}\text { Terceiro } \\
\text { estilo }\end{array}$ & $\begin{array}{l}\text { Terceiro } \\
\text { estilo }\end{array}$ & $\begin{array}{l}\text { Terceiro } \\
\text { estilo }\end{array}$ & $\begin{array}{l}\text { Terceiro } \\
\text { estilo }\end{array}$ & $\begin{array}{l}\text { Terceiro } \\
\text { estilo }\end{array}$ \\
\hline Sexo & Sexo & Sexo & Sexo & Sexo & Sexo \\
\hline Idade & Idade & Idade & Idade & Idade & Idade \\
\hline $\begin{array}{l}\text { Localização } \\
\text { Geográfica }\end{array}$ & $\begin{array}{l}\text { Localização } \\
\text { Geográfica }\end{array}$ & $\begin{array}{l}\text { Localização } \\
\text { Geográfica }\end{array}$ & $\begin{array}{l}\text { Localização } \\
\text { Geográfica }\end{array}$ & $\begin{array}{l}\text { Localização } \\
\text { Geográfica }\end{array}$ & $\begin{array}{l}\text { Localização } \\
\text { Geográfica }\end{array}$ \\
\hline
\end{tabular}

Figura 2 - Exemplo de Cromossomo (Grupos com 6 integrantes)

- A população inicial do algoritmo genético é gerada a partir do número de alunos do curso e das informações contidas no banco de dados dos cursos;

- O número de genes do cromossomo é igual ao número de integrantes de cada grupo (utilizam-se grupos com no máximo 6 alunos);

- Para avaliar cada cromossomo utiliza-se o cálculo de penalidades. A função de avaliação atribui penalidades associadas ao cromossomo. Estas penalidades são calculadas de acordo com o tipo de grupo (homogêneo ou heterogêneo) e os critérios definidos pelo professor; A avaliação segue a fórmula:

$$
f(x)=\frac{1}{1+\Sigma \text { penalidades }(x)}
$$

onde $f o(x)$ representa o valor de retorno da função de avaliação, aplicada ao indivíduo $x$ e penalidades $(x)$ as penalidades a ele associadas.

- O algoritmo genético é executado repetidas vezes. A cada geração, o melhor cromossomo representa um dos grupos formados e é extraído da população. O algoritmo genético é executado, novamente, com os alunos restantes, para a formação dos demais grupos.

Para a função de avaliação foram utilizadas as seguintes penalidades:

- não devem existir, preferencialmente, dois membros do grupo com o mesmo papel, principalmente com o papel de coordenador;

- se o grupo formado deve ser heterogêneo, de acordo com os critérios definidos pelo professor, se a maioria dos componentes estiver enquadrada num dos critérios definidos, haverá uma penalização. Da mesma forma, se o grupo formado deve ser homogêneo, se a maioria dos componentes divergir 
dos critérios definidos pelo professor, haverá uma penalização. Estas penalidades são atribuídas para cada um dos critérios definidos na formação dos grupos;

O cromossomo que tiver a menor penalidade é o mais adequado e será um dos grupos escolhidos. Os algoritmos genéticos facilitam a codificação de problemas com diversos tipos de restrição, mesmo quando as mesmas apresentem diferentes graus de importância. Neste caso, se dois indivíduos violam restrições, é considerado mais apto aquele que viola as mais flexíveis (soft constrains) em detrimento do que viola as mais graves (hard constrains) (Barbosa, 1996). No algoritmo elaborado neste trabalho, é considerado mais apto o indivíduo que tem o menor número de penalidades, ou seja, que viola o menor número de restrições. O algoritmo é executado repetidamente, até que sejam formados todos os grupos desejados. A cada nova geração, são extraídos da população os alunos que já foram agrupados, para evitar que um mesmo aluno faça parte de mais de um grupo.

Ao final do algoritmo, são apresentados os integrantes de cada grupo, além dos papéis que cada integrante deve assumir (preferencialmente). Estas informações também são cadastradas automaticamente na ferramenta Grupos do TelEduc, para que o professor não precise cadastrar os seus grupos manualmente.

Um ponto importante diz respeito à forma de geração da nova população e da aplicação dos operadores genéticos. Uma das técnicas mais comuns para a geração da nova população é a aplicação da técnica da roleta. Além disso, também são utilizados operadores genéticos como os de mutação e inversão. No caso do trabalho aqui apresentado, em que cada indivíduo da população representa um grupo, esta técnica e estes operadores não puderam ser aplicados, pois as informações dos alunos (dados cadastrados) não podem ser alterados, além do fato de que o mesmo aluno não pode integrar mais de um grupo.

Com relação à formação dos grupos, Antunes (s.d.) coloca que são 3 os processos mais comuns: 1) o grupo natural: o professor convoca seus alunos a formarem seus grupos que, normalmente, já existem; 2) o grupo artificial: é desejável quando se pretende sua constituição imediata; 3) sociometria: através da sociometria é possível identificar-se a potência de liderança e condições de ajustamento, contribuindo desta maneira para melhorar as relações sociais das classes e dos grupos; através de um sociograma é possível representar fatos sociais (pode ser utilizada para alunos que já se conhecem e estão juntos, numa sala de aula presencial). No caso da aplicação em EAD, as opções 1 e 3 são dificultadas, pois os alunos não se conhecem e não estão reunidos presencialmente. Sendo assim, é preciso realizar a formação dos grupos de forma artificial. Quanto aos critérios para formação dos grupos, Antunes (s.d.) cita: nível de desenvolvimento intelectual, aptidões e domicílios (para facilitar reuniões extraclasse).

No trabalho aqui apresentado os critérios citados podem ser definidos pelo professor. O nível de desenvolvimento intelectual e as aptidões são compreendidos pelo modelo de aluno, através da identificação dos estilos cognitivos dos alunos. O item domicílio corresponde à localização geográfica dos alunos que estão atuando no ambiente de EAD.

Com relação à definição dos papéis de cada um dos integrantes, Antunes (s.d., 0. 60) coloca que "Embora seja possível encontrar ou admitir grupos em que não existam funções específicas para seus membros, deve o professor sugerir que cada membro do grupo tenha uma ou mais funções específicas...". Segundo os padrões estilísticos 
propostos por Butler (2003) e através dos resultados das pesquisas desenvolvidas por Bariani (1998) e Geller (2004), são considerados os 3 estilos cognitivos preferenciais dos alunos para a identificação dos papéis, como demonstrado na Figura 2. A Figura 3 apresenta a interface que permite a definição dos critérios para o estabelecimento dos grupos.

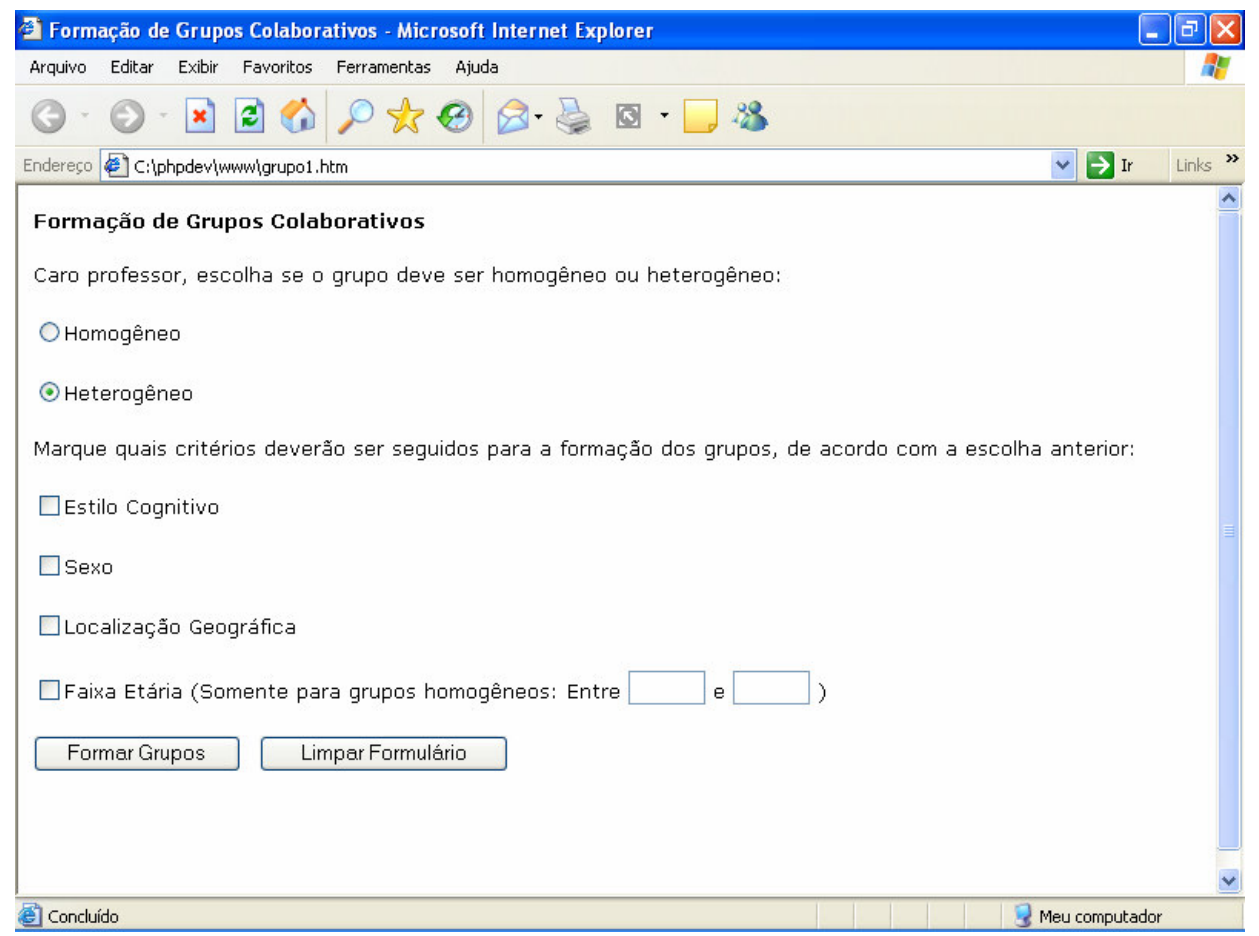

Figura 3: Assistente para Formação dos Grupos Colaborativos

\section{VALIDAÇÃO DO AGENTE FORMA GRUPO COLABORATIVO}

A validação do agente forma grupo colaborativo foi realizada através de um estudo de caso (Yin, 2001), envolvendo três turmas de cursos superiores da área de Informática. Antes de realizar a aplicação da formação de grupos colaborativos proposta com os grupos de controle, foi realizado um pré-teste, envolvendo os alunos da disciplina de Algoritmos e Programação II, da FACENSA. Este pré-teste serviu para identificar pontos que precisaram ser melhorados para a validação adequada nos demais grupos. No pré-teste, uma turma de 11 alunos foi dividida em dois grupos. Cada um dos grupos recebeu a tarefa de implementar um programa diferente, seguindo alguns critérios estabelecidos. Neste pré-teste, os alunos decidiram a formação dos grupos e a definição dos papéis, a partir dos papéis estabelecidos pelo professor. Cada um dos alunos preencheu o questionário (conforme instrumento elaborado por Bariani (1998)) para que fosse possível identificar o seu estilo cognitivo. A maior dificuldade no desenvolvimento dos trabalhos foi a falta de planejamento e indefinição das tarefas dos integrantes. Mesmo com a definição dos papéis, os alunos tiveram dificuldade para trabalhar em equipe. Nos dois grupos, os integrantes que mais atuaram foram os que tinham maior domínio do conteúdo necessário para o desenvolvimento do trabalho que era, no caso, o de programação, ou seja, o que mais se destacou foi o conhecimento na linguagem de programação utilizada e não a lógica do programa a ser implementado. Como conclusões a partir do pré-teste, observou-se que: 
- além de estabelecer os papéis de cada integrante, era preciso definir, com maior clareza, quais as tarefas que cada um dos papéis deveria realizar;

- a tarefa não foi escolhida adequadamente pois, não permitiu o funcionamento adequado da equipe. Segundo Coll (et al., 1996, p. 306), "as tarefas mais 'abertas'nas quais os participantes devem selecionar a informação relevante e, com várias soluções possíveis, promovem a colaboração e os intercâmbios comunicativos em maior medida que as tarefas mais 'fechadas' - com diretrizes e informações claramente especificadas e soluções estabelecidas";

- alguns dos papéis propostos têm suas tarefas que se enquadram em mais de um papel, como é o caso dos papéis de coordenador e de planejador;

- nem todos os grupos têm integrantes com perfis para preencherem todos os papéis estabelecidos.

Estas conclusões permitiram a readequação das estratégias, para estabelecer os grupos de controle e realizar o estudo de caso proposto. As três principais modificações foram: 1) a modificação do estilo do trabalho proposto (deixou de ser um trabalho de implementação e passou a ser um trabalho de construção colaborativo); 2) a junção dos papéis de coordenador e planejador e 3) a definição das tarefas de cada um dos papéis estabelecidos. Foram formados os seguintes grupos de controle:

- grupos formados espontaneamente, com definição de papéis também espontânea, compostos pelos alunos da disciplina de Algoritmos e Programação do UniRitter, totalizando 27 alunos;

- grupos formados pelo agente forma grupo colaborativo, sem definição de papéis (definição de papéis espontânea), compostos pelos alunos da disciplina de Algoritmos e Programação I da FACENSA, totalizando 16 alunos;

- grupos formados pelo agente forma grupo colaborativo, com definição automática de papéis, de acordo com os estilos cognitivos dos alunos, compostos pelos alunos da disciplina de Algoritmos e Programação I da ULBRA, totalizando 21 alunos.

Para os três grupos foi aplicada a mesma atividade, que consistiu num trabalho de grupo, integrando os conteúdos estudados na disciplina com a realidade do mercado. A partir dos conceitos de programação estudados em aula, os alunos realizaram uma pesquisa sobre uma determinada linguagem de programação (diferente da estudada na disciplina). Além de apresentar informações sobre esta linguagem de programação, os alunos realizaram uma pesquisa de vagas no mercado de trabalho e uma pesquisa com empresas e/ou profissionais atuando na área de desenvolvimento de software. Nos grupos de controle da FACENSA e da ULBRA, os integrantes de cada grupo foram escolhidos de forma automática pelo agente forma grupo colaborativo, através da escolha de grupos heterogêneos de acordo com o estilo cognitivo. Esta escolha baseouse na afirmação de Franco (1995), que coloca que é importante a formação de grupos heterogêneos, para que seja possibilitada a interação entre alunos com diferentes níveis de construção cognitiva e nas afirmações de Barreiros (s.d.) e Franco (1995), quando afirmam que a heterogeneidade grupal ao nível das aptidões e perfis de personalidade gera mais eficácia que a homogeneidade, pois permite que existam oposições entre os pontos de vista do grupo.

Nas três disciplinas a metodologia empregada é a Problem Based Learning. Segundo esta metodologia, a estratégia de ensino é apresentar aos alunos questões problema. Os alunos realizaram a apresentação do trabalho de forma presencial. A avaliação dos resultados obtidos foi realizada em dois momentos: 1) avaliação dos resultados do trabalho pelo professor e 2) auto-avaliação do grupo. A forma de avaliação foi baseada na afirmação de Bonals (2003, p. 149): "podemos avaliar o produto final elaborado pelo grupo, ou ainda aquilo que cada componente aprendeu 
mediante sua elaboração. Também é possível propor uma auto-avaliação: que o grupo, ou cada integrante, se auto-avalie".

Considerações Finais

O trabalho apresentado não pretendeu realizar a comparação entre os algoritmos genéticos e outras técnicas possíveis de otimização. Os algoritmos genéticos buscam uma solução ótima, partindo de várias soluções simultaneamente, enquanto que os métodos clássicos de otimização efetuam a busca voltados a uma única solução a cada instante. Isto permite que se encontre a melhor solução ótima dentre todas as possíveis soluções. Além disso, os algoritmos genéticos, por utilizarem os princípios da evolução e da genética, são capazes de direcionar suas buscas de uma maneira mais eficiente do que um processo aleatório. O problema da formação dos grupos é considerado de escalonamento, apresentando grande dificuldade em seu tratamento principalmente por 1) pertencerem à classe de problemas NP completo, ou seja, a partir de um tamanho razoável dos dados de entrada torna-se impossível explorar todo o espaço de busca e 2) devem levar em conta restrições que com freqüência estão fortemente vinculadas ao conhecimento específico do domínio no qual estão inseridas (Davis, 1991). Estas afirmações justificam a escolha da técnica aplicada para a formação de grupos neste trabalho.

A análise dos resultados do estudo de caso realizado demonstraram que os grupos de controle que tiveram a aplicação do agente forma grupo colaborativo obtiveram um desempenho superior ao grupo de controle que realizou o agrupamento de forma aleatória. Além disso, o grupo de controle em que os alunos assumiram os papéis também estabelecidos pelo agente forma grupo colaborativo teve um desempenho significativamente superior aos demais grupos.

Nos ambientes virtuais de EAD, os alunos, na maioria das vezes, não se conhecem pessoalmente e/ou não se encontram de forma presencial mas, a cooperação/colaboração continua sendo importante para o estabelecimento das relações sociais. Os recursos tecnológicos tendem a aproximar as pessoas e não separá-as, ao contrário do que se possa pensar, como é o caso dos telefones celulares, um recurso tecnológico tão utilizado atualmente, para facilitar a comunicação e a aproximação das pessoas.

\section{REFERÊNCIAS BIBLIOGRÁFICAS}

ANTUNES, C. Técnicas Pedagógicas de Dinâmica de Grupo. Editora do Brasil, s. d. BAQUERO, R. Vygostky e a Aprendizagem Escolar. Porto Alegre: Artes Médicas, 1998.

BARBOSA, H. J. C. Algoritmos genéticos para otimização em engenharia: uma introdução. IV Seminário sobre Elementos Finitos e Métodos Numéricos em Engenharia. Juiz de Fora, MG: s. e., 1996. Anais...

BARIANI, Isabel Cristina Dib Estilos Cognitivos de Universitários e Iniciação Científica. 1998. Tese (doutorado) - UNICAMP.

BARREIROS, João. A Turma como Grupo e Sistema de Interação: uma abordagem sistêmica da comunicação na turma. Portugal: Porto Editora, s.d. (Coleção Escola e Saberes). 
BONALS, Joan. O trabalho em pequenos grupos na sala de aula. Porto Alegre: Artmed, 2003.

BRUSILOVSKY, Peter. Methods and Techniques of Adaptive Hypermedia. User Modelling and User Adapted Interaction, 1996, v.6, n. 2-3, p. 87-129. Special Issue on Adaptive Hypertext and Hypermedia.

BRUSILOVSKY, Peter; MAYBURY, M. T. From Adaptive Hypermedia to the Adaptive Web. Communications of the ACM. May 2002, Vol. 45, N. 5.

BUTLER, K. A. Estilos de Aprendizagem: as dimensões psicológica, afetiva e cognitiva. Porto Alegre: Editora da UFRGS, 2003.

CARNEIRO, Mára Lúcia Fernandes. O Acoplamento Tecnológico e a Comunicação em Redes. 2003. Tese (doutorado) - Universidade Federal do Rio Grande do Sul, Pós-Graduação em Informática na Educação.

COLL, Cesar et al. Interação entre alunos e aprendizagem escolar In: Desenvolvimento Psicológico e Educação: psicologia da educação. Vol. 2. Porto Alegre: Artes Médicas, 1996.

DAVIS, L. Handbook of Genetic Algorithms. New York: Van Nostrand Reinhold, 1991.

FRANCO, Sérgio Kieling. O Construtivismo e a Educação. 4. ed. Porto Alegre: Mediação, 1995.

GELLER, Marlise. Educação a Distância e Estilos Cognitivos: Construindo um Novo Olhar sobre os Ambientes Virtuais. 2004. Tese (doutorado) - Universidade Federal do Rio Grande do Sul, Pós-Graduação em Informática na Educação.

MINICUCCI, Agostinho. Dinâmica de Grupo: teorias e sistemas. São Paulo: Atlas, 1997.

SALVADOR, C. C. Estrutura Grupal, Interação entre Alunos e Aprendizagem Escolar In: Aprendizagem Escolar e Construção do Conhecimento. Porto Alegre: Artes Médicas, 1994.

YIN, R. K. Estudo de Caso: planejamento e métodos. 2. ed. Porto Alegre: Bookman, 2001. 